\title{
Physiologic left ventricular reconstruction: Shape, function, and time recaptured
}

\author{
Gerald D. Buckberg, MD
}

\footnotetext{
From the Department of Cardiac Surgery, David Geffen School of Medicine at UCLA, Los Angeles, Calif. Disclosures: Author has nothing to disclose with regard to commercial support.

Received for publication March 28, 2016; accepted for publication March 30, 2016; available ahead of print May $18,2016$.

Address for reprints: Gerald D. Buckberg, MD, Department of Cardiac Surgery, David Geffen School of Medicine at UCLA, 62-258 CHS, 10833 Le Conte Ave, Los Angeles, CA 90095 (E-mail: gbuckberg@mednet.ucla.edu). J Thorac Cardiovasc Surg 2016;152:392-3

$0022-5223 / \$ 36.00$

Copyright (C) 2016 by The American Association for Thoracic Surgery

http://dx.doi.org/10.1016/j.jtcvs.2016.03.068
}

The surgical goal of recapturing normality is emphasized by Cirillo and colleagues 1 in their report of time analysis of physiologic left ventricular (LV) reconstruction, as his database on surgical ventricular restoration shows $0 \%$ hospital mortality and no worsening heart failure symptoms 7.9 years post operatively in patients with ischemic cardiomyopathy. The power of this study lies in addressing normality, recognizing its disruption by disease, and then rebuilding the normal ventricular ellipse.

\section{STRENGTHS}

Anatomy is the highlight. The objective is to restore the helical framework, which becomes spherical with heart failure. $^{2,3}$ The Fontan suture is not done, but a resulting conical form is demonstrated. Attaining this shape sets the stage for placing a longitudinal suture line using a narrow patch extending from the apex to the septum (just beneath the aortic valve). The terminal upper point may contain either normal muscle or scar tissue (which may end in the lower septum). ${ }^{4}$ Restoration of form, not merely disease exclusion, has become a surgical goal. Isomura and associates $^{5}$ demonstrated the importance of rebuilding shape versus simply reducing LV size, reporting an $86 \%$ 8-year survival rate in patients with hearts of the same size as in the study of Cirillo and colleagues, ${ }^{1}$ and an overall long-term survival of $72 \%$ versus $61 \%$ with a "shape" yardstick.

The second strength is restoring ventricular function, as measured by returning cardiac torsion... with one helical arm rotating clockwise (base) and the other counterclockwise (apex). Finally, the role of time is addressed. Surgical reconstruction changes anatomy, but adequate time is needed to rebuild the previously stretched collagen of a spherical heart, whose matrix metalloproteinase half-life is $>120$ days. $^{6}$

Cirillo's results by returning normal shape differed from the flawed STICH trial, where the pre operative spherical shape was unchanged. ${ }^{7}$ They concluded that LV reconstruction is not different from CABG, yet lowered LV volume falls $19 \%$ (vs $51 \%$ here). ${ }^{8}$ Consequently, STICH deprived

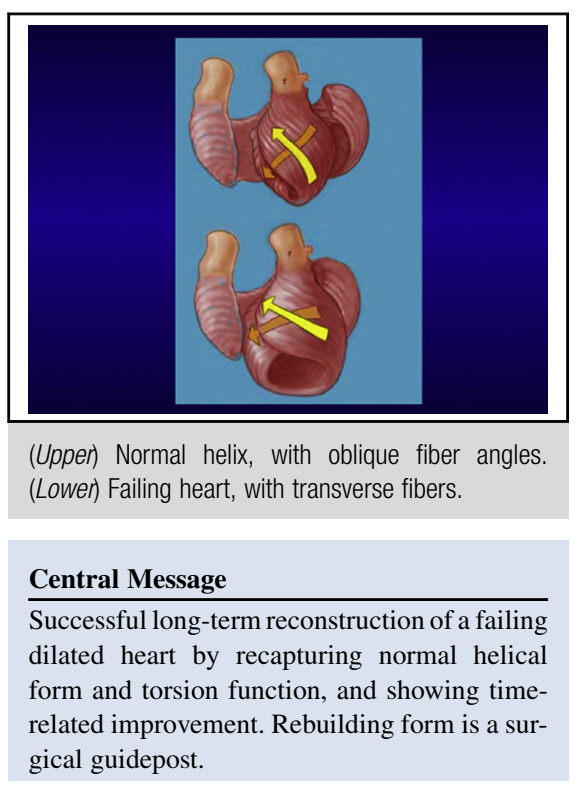

See Article page 382.

many patients of a sound procedure because of its improper patient selection and inadequate surgical expertise.

\section{WEAKNESSES}

First, a role for a wider patch should be considered when $\mathrm{LV}$ reconstruction is done before remote muscle is stretched, for example, early after myocardial infarction. This would avoid producing a restrictive LV size when excluding the scar. Second, inclusion of the sphericity index (ventricular length/width) would document a spherical chamber preoperatively, and confirm postoperative physiologic reconstruction. Finally, all recovery occurs at the apex, because the base rotates only marginally. Where are comparative normal base values, and what was the mitral annulus width? Could this imply that the base should be narrowed by an annular ring?

\section{OVERALL IMPRESSION}

This splendid study emphasizes our responsibility for rebuilding normal anatomy and function. These endpoints require an understanding of the guideposts of normality. The mechanics of the twisting motion for torsion call for LV rebuilding that restores the natural form and prevents intraoperative muscular injury from inadequate cardiac protection. When achieved, these vital form and function endpoints are reproducible, and cannot be offset by the 
flawed prospective randomized STICH Trial, which reports noncredible data.

\section{References}

1. Cirillo M, Campana M, Brunelli F, Dalla TM, Mhagna Z, Messina A, et al. Time series analysis of physiologic left ventricular reconstruction in ischemic cardiomyopathy. J Thorac Cardiovasc Surg. 2016;152:382-91.

2. Buckberg G, Hoffman JI, Mahajan A, Saleh S, Coghlan C. Cardiac mechanics revisited: the relationship of cardiac architecture to ventricular function. Circulation. 2008;118:2571-87.

3. Buckberg GD, Hoffman JI, Coghlan HC, Nanda NC. Ventricular structurefunction relations in health and disease, part II: clinical considerations. Eur J Cardiothorac Surg. 2015;47:778-87.

4. Buckberg GD. Editorial comment: surgical planning for surgical ventricular restoration involves decision options on form versus disease. Eur J Cardiothorac Surg. 2010;37:1100-3.
5. Isomura T, Hoshino J, Fukada Y, Kitamura A, Katahira S, Kondo T, et al Volume reduction rate by surgical ventricular restoration determines late outcome in ischaemic cardiomyopathy. Eur J Heart Fail. 2011;13: 423-31.

6. Caulfield JB, Janicki JS. Structure and function of myocardial fibrillar collagen. Technol Health Care. 1997;5:95-113.

7. Choi JO, Daly RC, Lin G, Lahr BD, Wiste HJ, Beaver TM, et al. Impact of surgical ventricular reconstruction on sphericity index in patients with ischaemic cardiomyopathy: follow-up from the STICH trial. Eur J Heart Fail. 2015; 17:453-63.

8. Michler RE, Rouleau JL, Al-Khalidi HR, Bonow RO, Pellikka PA, Pohost GM, et al; STICH Trial Investigators. Insights from the STICH trial: change in left ventricular size after coronary artery bypass grafting with and without surgical ventricular reconstruction. J Thorac Cardiovasc Surg. 2013; 146:1139-45.

9. Buckberg G, Athanasuleas C, Conte J. Surgical ventricular restoration for the treatment of heart failure. Nat Rev Cardiol. 2012;9:703-16. 